\title{
A Comparative Study of Effect of Untreated and Anaerobically treated Distillery Effluent on the Seedling Growth of Potato (Solanum tuberosum CV G4) \\ Neelu Verma ${ }^{1}$, Anil Kumar Dhiman ${ }^{2} *$ \\ ${ }^{1}$ Department of Biosciences, D.A.V. College Muzaffarnagar (Uttar Pradesh) India \\ ${ }^{2}$ Gurukul Kangri University, Haridwar (Uttarakhand) India
}

\author{
*Corresponding Author: \\ Anil Kumar Dhiman \\ Email: akvishvakarma@ rediffmail.com
}

\begin{abstract}
Industrial effluent is a favourable approach for irrigation demand. But according to an estimate, the alcohol production in India has reached 2.7 million liters and the proportion of effluent is nearly 15 times of the total alcohol production. This massive quantity, approximately 40 billion liters of effluents, if disposed untreated can cause considerable stress on water sources leading to widespread damage to aquatic life. The pollution effect of distillery waste is due to high bio-chemical oxygen demand (BOD) and colour. The present study compares the effect of untreated and anaerobically treated distillery effluent on seedling growth of potato (Solanum tuberosum). It is observed that potato seedling shows less growth in different concentration $(5 \%, 10 \%, 15 \%$, respectively) of untreated effluent as compared to anaerobically treated effluent. The result of this study indicates that we should use the treated effluent for irrigation purposes.
\end{abstract}

Keywords: Anaerobically treated effluent, BOD, Lagoon sludge, Untreated effluent.

\section{INTRODUCTION}

Increasing population and living standard have created an unprecedented demand of water for various alternative uses. As the economy expands, competing inter-sectoral and intra-sectoral demands for the water use increase. Further with the increase in population and with high degree of agriculture water, the need of this sector is also increasing. Due to limited water resources, the availability of water to meet requirement is severe. The ultimate irrigation potential of India has been estimated to be 140 mha. Out of this, 76 mha would come from surface water and 64 mha from ground water sources. The calculations by Kumar et al. [1] indicate that by the year 2025, the water requirements for irrigation would be $561 \mathrm{Km}^{3}$ for lowdemand scenario and $611 \mathrm{Km}^{3}$ for high-demand scenario. These requirements are likely to further increase to $628 \mathrm{Km}^{3}$ for low-demand scenario and 807 $\mathrm{Km}^{3}$ for high-demand scenario by 2050 . While the data of Central Pollution Control Board (CPCB) indicates that water consumption by industry accounts for $8 \%$ of the total national water use in India. By 2050, this will become almost four times the water used now [2]. So with the industrialization, for the continuous increase in the quantum of waste water, environmentally sound methods of waste water disposal are being sought.

Indian Standard Institute (ISI) has recommended various standards for the disposal of industrial waste water into rivers, lakes and the marine area to protect water quality and aquatic life from water pollution. Water pollution inflicts economic burden on the users of water resources. It imposes costs on municipal and industrial water supply and irrigation and damages variety of water based including recreational activities and commercial finishing [3]. Distillery effluent is acidic in nature ( $\mathrm{pH} 3.4$ to 5.1) and has very high BOD value $(22,000-48,650 \mathrm{mg} / \mathrm{l})$. That's why, now a days, effluent treatment plants (ETP) or Bio-gas plants have been set up with most of the distilleries plants where the effluent is first anaerobically treated and then aerobically, so that the final effluent is less polluted and it can be used directly for irrigation purpose.

\section{Earlier Studies}

Subba Rao [4] from a small scale one year field trial concluded that addition of anaerobically treated and diluted spent wash has no deleterious effect on sugarcane crop yield. Some other studies on the effect of distillery's effluent as source of irrigation on different crop plants have been made [5-16]. The results of these studies in general indicate that the pure distillery effluent as such or at high concentrations has deleterious effects on overall growth of different crop plants. Keeping these above points in view, this study was carried out for the relative effect of untreated or Raw spent wash (RSW), anaerobically treated or 
Biomethanated spent wash (BSW) and finally treated distillery effluents or Lagoon sludge (LS) in the different concentrations on the growth and yield performance of locally grown vegetable crop to assess the possible use of distillery effluents as fertilizer. Every year, various crops are grown in the field throughout India and many of them also used as medicine for different ailments [17]. But potato is commonly grown as a vegetable crop.

\section{MATERIALS AND METHODS}

This study was carried out with the sample of effluents from Sir Shadi Lal Distillery and Chemical Works (SSLD and CW), Muzaffarnagar. The distillery was set up in the year in 1960. SSLD and CW is one of the well known distilleries of the region. Its manufacturing unit is situated in Mansurpur in district Muzaffar Nagar in the western belt of the Indian state of Uttar Pradesh. The farmers of the adjoining areas for irrigating the crops use its effluent. For the present study, two types of treatments were applied to locally grown vegetable i.e. potato (Solanum tuberosum cv. G4). The pure (untreated ) effluent (raw spent wash) was diluted using normal distilled or tap water in different concentrations, viz. 1.0, 2.0, 2.5, 5.0, 10, 15, 20,25, 30, 35,40 percent etc. Similarly, pattern for the different concentrations of anaerobically treated effluent was used. For observing the seedling growth, ten days old seedling were analyzed for the following parameters -

- Seedling length

- Root length

- Shoot length

- Number of lateral roots formed

- Fresh weight of root

- Fresh weight of shoot

- Dry weight of root

- Dry weight of shoot

For the seed germination studies, the pure effluent (raw spent wash) was diluted using normal tap water in different concentrations viz. 1.0, 2.0, 2.5, 5.0, $10,15,20,25,30,35,40,45,50,75,100$ percent. The normal tap water as such served as 'control'. 25 uniform seeds of same size and colour of each sample were selected for experiment and they were surface sterilized with one percent mercuric chloride for two minutes. After washing under running tap water, the seeds were placed in sterilized petridishes lined with filter papers. The seeds in petridishes were moistened with $10 \mathrm{ml}$ of each of the following concentrations of distillery effluent on alternate days $(1.0 \%, 2.0 \%, 2.5 \%$ $100 \%)$ A control was maintained with distilled water.

Observations were taken daily at a fixed time. The experiments with different seeds were conducted in sequence and each treatment had its three replicates. For observing the seedling growth, five 10 days old seedling were picked from each of the sets and the length of the root and shoot were recorded. These seedlings dissected out and length, fresh weight and dry weight of these seedlings parts were recorded. In case of residual cotyledons, only the fresh and dry weight was recorded as suggested by Agarwal [18].

\section{RESULTS AND DISCUSSION}

First have a look on the seedling growth of Solanum tuberosum cv. G-4 in untreated distillery effluent. Table 1 and 2 show that in potato seedling growth is promoted in lower concentrations of distillery effluent and retards in higher concentrations of effluent as compared to the controlled one. On $10^{\text {th }}$ day root length in control, 1, 2, 2.5, 5, 10, 15 and $20 \%$ concentration were $5.90,6.00,6.20,6.36,5.80,5.40$, 5.00 and $3.30 \mathrm{~cm}$ respectively. While, it shows no growth at all at $25 \%$ and above concentration of untreated distillery effluent. Further at the same day, the shoot length in control, 1, 2, 2.5, 5, 10, 15 and $20 \%$ concentrations were $6.20,6.63,6.80,6.50,6.41,6.18$, 5.40 and $3.80 \mathrm{~cm}$ respectively.

Table -1: Effect of Untreated Distillery Effluent on the Seedling Length (Root Length and Shoot Length) Roots of 10 days Old Potato (Solanum tuberosum cv. G -4) Seedlings

\begin{tabular}{|l|l|l|l|}
\hline Effluent concentration $(\%)$ & Seedling length $(\mathrm{cm})$ & Root length $(\mathrm{cm})$ & Shoot length $(\mathrm{cm})$ \\
\hline Control & $12.10 \pm 1.26$ & $5.90 \pm 0.20$ & $6.20 \pm 1.00$ \\
\hline 1 & $12.63 \pm 2.00^{*}$ & $6.00 \pm 0.13^{*}$ & $6.63 \pm 1.20^{* *}$ \\
\hline 2 & $13.00 \pm 1.50^{* *}$ & $6.20 \pm 0.36^{*}$ & $6.80 \pm 0.85 \dagger$ \\
\hline 2.5 & $12.86 \pm 0.8 \dagger^{\dagger}$ & $6.36 \pm 0.40 \dagger$ & $6.50 \pm 0.30 \dagger$ \\
\hline 5 & $12.21 \pm 1.11^{*}$ & $5.80 \pm 0.50^{*}$ & $6.41 \pm 1.10^{* *}$ \\
\hline 10 & $11.58 \pm 1.10^{*}$ & $5.40 \pm 0.25^{*}$ & $6.18 \pm 1.19 \dagger$ \\
\hline 15 & $10.40 \pm 0.05 \dagger$ & $5.00 \pm 0.02^{*}$ & $5.40 \pm 1.68^{* *}$ \\
\hline 20 & $7.10 \pm 1.00 \dagger$ & $3.30 \pm 0.80 \dagger$ & $3.80 \pm 1.11 \dagger$ \\
\hline 25 & 00 & 00 & 00 \\
\hline 30 & - & - & - \\
\hline 35 & - & - & - \\
\hline 40 & - & - & - \\
\hline 45 & - & - & - \\
\hline 50 & - & - & - \\
\hline 75 & - & - & - \\
\hline 100 & - & - & - \\
\hline
\end{tabular}

Note: Values are in mean $\pm \mathrm{SD}$; Significance of difference from control; ${ }^{*} \mathrm{p}<0.05 ;{ }^{*} \mathrm{p}<0.01$ and $\dagger$ non significant 
Thus, results in table 1 indicates that in lower concentration of untreated distillery effluent the root and shoot length as well as other parameters are slightly promoted, as compared to the control and at $25 \%$ of effluent, there is no growth. Thus, seedlings show total retardation in growth proving the toxic effects of untreated distillery effluent. The fresh and dry weights of root and shoot also show similar trends as indicated in Table 2.

Table-2: Effect of Untreated Distillery Effluent on the Seedling Weight (Root Weight and Shoot Weight) of 10 days old Potato (Solanum tuberosum cv. G -4) Seedlings

\begin{tabular}{|c|c|c|c|c|}
\hline \multirow{2}{*}{$\begin{array}{l}\text { Effluent } \\
\text { concentration (\%) }\end{array}$} & \multicolumn{2}{|c|}{ Fresh weight(mg) } & \multicolumn{2}{|c|}{ Dry weight(mg) } \\
\hline & Root & Shoot & Root & Shoot \\
\hline Control & $16.13 \pm 2.50$ & $16.80 \pm 1.14$ & $4.03 \pm 1.00$ & $4.20 \pm 0.50$ \\
\hline 1 & $16.44 \pm 1.00 *$ & $17.06 \pm 1.53 *$ & $4.11 \pm 1.25^{*}$ & $4.26 \pm 0.10^{*}$ \\
\hline 2 & $16.73 \pm 1.17 *$ & $17.38 \pm 1.02 *$ & $4.18 \pm 1.15^{*}$ & $4.34 \pm 0.26^{*}$ \\
\hline 2.5 & $16.56 \pm 2.14 *$ & $17.11 \pm 1.66^{*}$ & $4.14 \pm 0.82 *$ & $4.27 \pm 0.05^{*}$ \\
\hline 5 & $16.02+2.00 *$ & $16.48 \pm 1.38^{*}$ & $4.00 \pm 1.09^{*}$ & $4.12 \pm 0.06^{*}$ \\
\hline 10 & $15.81 \pm 3.15^{*}$ & $16.09 \pm 1.42 *$ & $3.95 \pm 1.11^{*}$ & $4.02 \pm 0.50 \dagger$ \\
\hline 15 & $14.05 \pm 1.50 *$ & $15.63 \pm 0.60 \dagger$ & $3.51 \pm 0.25^{*}$ & $3.75 \pm 0.10 \dagger$ \\
\hline 20 & $9.47 \pm 1.08 \dagger$ & $11.00 \pm 1.39 \dagger$ & $2.36 \pm 0.60 \dagger$ & $2.64 \pm 0.05 \dagger$ \\
\hline 25 & 00 & 00 & 00 & 00 \\
\hline 30 & - & - & - & - \\
\hline 35 & - & - & - & - \\
\hline 40 & - & - & - & - \\
\hline 45 & - & - & - & - \\
\hline 50 & - & - & - & - \\
\hline 75 & - & - & - & - \\
\hline 100 & - & - & - & - \\
\hline
\end{tabular}

Note: Values are in mean $\pm \mathrm{SD}$; Significance of difference from control; ${ }^{*} \mathrm{p}<0.05 ;{ }^{*} \mathrm{p}<0.01$ and $\dagger$ non significant

Coming to the seedling growth in Solanum tuberosum cv. G-4 in anaerobically treated effluent, it is seen from Table 3 and 4 show that in potato seedling, the growth slightly promotes in lower concentration of distillery effluent and retards in higher concentrations of effluent as compared to the control. On $10^{\text {th }}$ day root length in control, 1, 2, 2.5, 5, 10, 15 and $20 \%$ concentrations were $5.90,6.20,6.40,6.60,6.15,6.00$, 5.30 and $4.00 \mathrm{~cm}$. respectively. While, it shows no growth at all at $25 \%$ or above concentrations in anaerobically treated distillery effluent. Further at the same day the shoot length in control, 1, 2, 2.5, 5, 10, 15, and $20 \%$ concentrations were $6.20,7.00,7.10,7.20$, $7.10,6.40,5.70$ and $4.20 \mathrm{~cm}$. respectively.

The results in table 3 indicates that in lower concentration of anaerobically treated distillery effluent the root and shoot length as well as other parameters show promotion in growth and in higher concentration show inhibition in growth as compared to the control and $25 \%$ above of this effluent, there is no growth. Seedling show total retardation in growth proving the toxic effects of anaerobically distillery effluent. Similar trends in fresh and dry weights were observed under effluent treatments as shown in Table 4.

Table-3: Effect of Anaerobically treated Distillery Effluent on the Seedling Length (Root Length and Shoot Length) Roots of 10 days old Potato (Solanum tuberosum cv. G -4) Seedlings

\begin{tabular}{|l|l|l|l|}
\hline Effluent concentration $(\%)$ & Seedling length $(\mathrm{cm})$ & Root length $(\mathrm{cm})$ & Shoot length $(\mathrm{cm})$ \\
\hline Control & $12.10 \pm 1.26$ & $5.90 \pm 1.20$ & $6.20 \pm 0.08$ \\
\hline 1 & $13.20 \pm 1.00^{*}$ & $6.20 \pm 0.11 \dagger$ & $7.00 \pm 0.33 \dagger$ \\
\hline 2 & $13.50 \pm 1.11^{*}$ & $6.40 \pm 0.20 \dagger$ & $7.10 \pm 0.12 \dagger$ \\
\hline 2.5 & $13.80 \pm 2.00^{*}$ & $6.60 \pm 0.1{ }^{*} \dagger$ & $7.20 \pm 0.32 \dagger$ \\
\hline 5 & $13.25 \pm 1.55^{*}$ & $6.15 \pm 0.71^{*}$ & $7.10 \pm 0.16^{\dagger}$ \\
\hline 10 & $12.40 \pm 0.12^{*}$ & $6.00 \pm 1.00^{*}$ & $6.40 \pm 0.11^{\dagger}$ \\
\hline 15 & $11.00 \pm 1.88^{*}$ & $5.30 \pm 0.01 \dagger$ & $5.70 \pm 0.56^{* *}$ \\
\hline 20 & $8.20 \pm 0.99 \dagger$ & $4.00 \pm 0.32 \dagger$ & $4.20 \pm 0.89 \dagger$ \\
\hline 25 & 00 & 00 & 00 \\
\hline 30 & - & - & - \\
\hline 35 & - & - & - \\
\hline 40 & - & - & - \\
\hline 45 & - & - & - \\
\hline 50 & - & - & - \\
\hline 75 & - & - & - \\
\hline 100 & - & - & - \\
\hline
\end{tabular}

Note: Values are in mean \pm SD; Significance of difference from control; ${ }^{*} \mathrm{p}<0.05 ;{ }^{*} \mathrm{p}<0.01$ and $\uparrow$ non significant 
There was inhibitory effect on seed germination when untreated distillery effluent or raw spent wash (RSW) was used. However, when anaerobically treated distillery effluent (BSW) was used during seed germination, it showed mostly inhibitory effect. The effect of untreated distillery effluent on seedling growth (root and shoot length, root and shoot weight and number of lateral roots) was also inhibitory. While, the effect of anaerobically treated distillery effluent in lower concentration was comparatively less inhibitory or promotory and it showed total inhibition in higher concentrations.

Table-4: Effect of Anaerobically treated Distillery Effluent on the Seedling Weight (Root Weight and Shoot Weight) of 10 days old Potato (Solanum tuberosum cv. G -4) Seedlings

\begin{tabular}{|c|c|c|c|c|}
\hline \multirow{2}{*}{$\begin{array}{c}\text { Effluent } \\
\text { concentration }(\%)\end{array}$} & \multicolumn{2}{|c|}{ Fresh weight(mg) } & \multicolumn{2}{|c|}{ Dry weight(mg) } \\
\hline & Root & Shoot & Root & Shoot \\
\hline Control & $16.13 \pm 1.50$ & $16.80 \pm 1.14$ & $4.03 \pm 1.00$ & $4.20 \pm 0.50$ \\
\hline 1 & $16.74 \pm 1.75 *$ & $17.88+1.32 *$ & $4.18 \pm 0.22 *$ & $4.47 \pm 0.10 *$ \\
\hline 2 & $16.94 \pm 1.36^{*}$ & $18.24 \pm 0.16^{*}$ & $4.23 \pm 0.02 *$ & $4.56 \pm 0.80 *$ \\
\hline 2.5 & $17.26 \pm 1.32 *$ & $18.47 \pm 1.99 *$ & $4.31 \pm 0.19 *$ & $4.62 \pm 0.16^{*}$ \\
\hline 5 & $17.10 \pm 0.32 *$ & $18.24 \pm 1.10 *$ & $4.27 \pm 0.68 *$ & $4.56 \pm 0.99 *$ \\
\hline 10 & $17.04 \pm 1.68 *$ & $16.90 \pm 1.55^{*}$ & $4.26 \pm 0.42 *$ & $4.22 \pm 0.05 \dagger$ \\
\hline 15 & $15.36 \pm 1.00 *$ & $15.64 \pm 1.30 *$ & $3.84 \pm 0.09 *$ & $3.91 \pm 0.10 *$ \\
\hline 20 & $12.36 \pm 1.16 \dagger$ & $13.00 \pm 1.32 \dagger$ & $3.09 \pm 0.10 *$ & $3.25 \pm 0.99 *$ \\
\hline 25 & 00 & 00 & 00 & 00 \\
\hline 30 & - & - & - & - \\
\hline 35 & - & - & - & - \\
\hline 40 & - & - & - & - \\
\hline 45 & - & - & - & - \\
\hline 50 & - & - & - & - \\
\hline 75 & - & - & - & - \\
\hline 100 & - & - & - & - \\
\hline
\end{tabular}

Note: Values are in mean \pm SD; Significance of difference from control; $* p<0.05 ; * * p<0.01$ and $\dagger$ non significant

Thus, the results show that untreated distillery effluent is more hazardous in comparison to anaerobically treated as it is rich in various toxic and undesirable chemicals, inorganic salts and their ions. The present work clearly shows the hazardous nature of pollutant present in distillery effluent when given in excess quantity. So, the distillery effluents are to be used for irrigation after dilution and final treatment. This may be a possible solution for the demand of water for irrigation of agriculture field, at least in the neighborhood of sugar mills and distillery plants.

\section{REFERENCES}

1. Kumar, R., Singh, R.D. \& Sharma, K.D. (2005). Water Resources in India. Current Science, 89 (5), 794-811.

2. CSE (Centre for Science and Environment). (2004). It is not Agriculture. A Down to Earth: Supplement. Available at: http://www.cseindia.org/dte-supplement/ industry20040215/agriculture.htm. Accessed 20 May 2016.

3. Dasgupta, A.K. \& Murty, M.N. (1985). Economic Evaluation of Water Pollution Abatement: A Case Study of Paper and Pulp Industry in India. Indian Economics Review, 20 (2), 231-267.

4. Subha Rao, B. (1974). Full Scale Treatment Plant results Treating Spent Wash on the Principles of Anoerobic Lagooning. Proc. All India Seminar on Distillery Waste Disposal Methods, (pp. 66-80), Sangli.
5. Bahadur, B. \& Sharma, B.K. (1990). Effect of Industrial Effluent on Seed Germination and Early Seedling Growth of Triticum aestivum var. UP 115. Acta Bot. Indica, 18 (1), 80-83.

6. Chidankumar, C.S., Chandraju, S. \& Nagendraswamy, R. (2009). Impact of Distillery Spent Wash Irrigation on the Yields of Top Vegetables (Creepers). World App. Sci. J., 6 (9), 1270-1273.

7. Elcey, CD. \& Tiwari, D. (1991). Effect of Distillery Effluent on Seed Germination, Early Seedling Growth and Chlorophyll Content of Millet Crop. Geobios, 18, 134-136.

8. Gautam, D.D. and Bishnoi, S. (1990). Studies on the Effects of Dairy Effluent and Soil Characteristics and Growth of Wheat Plant. $A d v$. PI., Sci. 3 (2), 236-244.

9. Hariom, Singh, N. and \& Arya, M.S. (1994). Combined Effect of Wastes of Distillery and Sugar Mill on Seed Germination, Seedling Growth and Biomass of Okra (Abelmoschus esculenntus (L) Moench. Environ. Biol., 15(1), 171-175.

10. Jabeen, D. \& Saxena, P.K. (1990). Effect of Industrial Effluent on Growth Behavior of Pisum sativum. Geobios, 11, 197-201.

11. Kannabiran, B. \& Pragason, A. (1993). Effects of Distillery Effluent on Seed Germination, Seedling Growth and Pigment Content of Vigna mungo (I.) Heper (cv.T 9.) Geobios, 20, 108-112.

12. Mukherjee, U. \& Sahai, R. (1988). Effect of Distillery Waste on Seed Germination, Seedling 
Establishment and Early Seedling Growth of Cajanas cajan. Acta Bot. Indica, 16, 182-185.

13. Sahai, R. Jabeen, S. \& Saxena, P.K. (1983). Effect of Distillery Waste on Seed Germination, Seedling Growth and Pigment Content of Rice. Indian J. Ecol., 10(1), 7-10.

14. Soundarrajan, M., Pitchai, G.J. \& Senthil Kumar, T. (2007). Effect of Distillery Spent Wash on Seed Germination, Seedling Growth and Yield of Bhindi Abelmoscus esculentum L. Moench. Adv. Plant. Sci., 20(1), 141-143.

15. Srivastava, N. \& Sahai, H. (1987). Effect of Distillery Waste on Performance of Cicer arietinum L. Environ. Pollut., 43, 91-102.

16. Verma, Neelu \& Dhiman, A.K. (2015). Effect of Untreated Distillery Effluents on Seed Germination and Seedling Growth of Chili (Capsicum annuum cv.shanti 389). Trends in Biosciences, 8 (13), 34423446.

17. Dhiman, A.K. (2006). Ayurvedic Drug Plants. New Delhi: Daya Publishing House.

18. Agarwal, R.L. (1980). Seed Technology, Oxford and IBH Publishing Company, New Delhi. 